\title{
Spatial Monetary Economic Growth with Housing and Residential Distribution over the Urban Area
}

\author{
Wei-Bin Zhang \\ Ritsumeikan Asia Pacific University, Beppu-shi, Japan \\ E-mail:wbz1@apu.ac.jp \\ Received May 26, 2011; revised July 5, 2011; accepted July 20, 2011
}

\begin{abstract}
This study introduces space, transportation, and money into an economic growth model. Growth theory neglects the importance of transportation on economic growth and transportation economics fails to properly explain how changes in transportation conditions (such as technological improvement, infrastructure investment, and oil prices) affect long-term economic growth. By proposing a growth model with transportations, we try to explain effects of transportation on economic growth. Our model describes dynamic interactions among capital accumulation, travel time, housing, residential distribution, amenity, and endogenous time distribution among work, travel, and leisure. The study examines effects of inflation policy, transportation conditions, and other conditions on long-term economic growth and economic geography. The paper demonstrates a way to integrating some important models in the literature in economic growth theory, urban economics, and transportation research so that the significance of transportation systems upon economies can be properly analyzed.
\end{abstract}

Keywords: Economic Growth, Capital Accumulation, Travel Speed, Leisure Time, Housing Rent, Land Rent, Inflation Policy, CIA Approach

\section{Introduction}

This study examines effects of transportation conditions and monetary policy on long-term economic growth. Although there are many models of economic growth, there are only a few formal economic growth models which explicitly introduce transportation conditions into economic growth theory. Nevertheless, it is obvious that changes in transportation conditions such as technological improvement, infrastructure investment and oil price will affect economic growth. Nevertheless, formal economic growth theory fails to explain how economic growth is related to transportation conditions. Another important issue which is seldom studied in the literature of spatial economics is how money affects spatial economic growth. It is well known that relations between economic growth and money have been extensively analyzed in the literature of economic growth since Tobin published his seminar work about growth and money in 1956. Relations between economic growth and transportation systems with money have been seldom examined in the literature of theoretical economics. Money and transportation systems connect almost all aspects of human interactions across space over time. As effects of transportation systems and money can be properly evaluated only over long period of time, a genuine dynamic approach to interactions, for instance, between transportation systems and economic development is required. Theoretical economics lacks a proper analytical framework for discussing these issues. A main reason for the omission of studying interactions of economic growth, money and transportation conditions is that the traditional economic growth lacks a suitable analytical framework.

The objective of this paper is to study monetary growth with economic geography and transport systems. This study is to introduce money into a dynamic model proposed by Zhang [1]. The model by Zhang deals with an interaction among capital accumulation, land, housing, environment, transportation in an isolated linear economy, by synthesizes the main ideas in the Solow growth model in the neoclassical growth theory, the Alonso urban model and the Muth housing model in the urban economics in an alternative framework to the traditional neoclassical growth theory. The main difference between this study and the model by Zhang is that this model introduces money into Zhang's model with the CIA approach. The paper is organized as follows. Section 2 defines the basic model. Section 3 guarantees existence of spatial equilibrium. Section 4 simulates the model with 
the Cobb-Douglas production function. Section 5 examines effects of change in the inflation policy, CIA parameter and transportation conditions on the spatial equilibrium. Section 6 concludes the study. Appendix A proves the main results in Section 3.

\section{The Model}

The model is a combination of the basic features of the four key models, the Solow growth model, the Alonso urban model, the Muth housing model in the neoclassical growth theory and urban economics, and the monetary growth model in the CIA approach. Most "real" aspects of the model are similar to the model proposed by [1], except that this study introduces money to the spatial economy. The monetary aspects of the model with the CIA approach are examined in a recent book on monetary growth theory by [2]. As far as urban structures are concerned, we follow the standard residential land-use model. The basic features of this model are that an isolated city state is built on a flat featureless plain. All residents in the economy work in the CBD. People travel only between their homes and the CBD. Travel is equally costly in terms of time and money in all directions. An individual may reside at only one location. The only spatial characteristic of any location that directly matters is the distance from the city center. The population is homogenous. The households achieve the same utility level regardless of where they locate. All the markets are perfectly competitive. The system is geographically linear and consists of two parts - the CBD and the residential area. The isolated state consists of a finite strip of land with fixed (territory) length, $L$, extending from the CBD with constant unit width. We assume that all economic activities are concentrated in the CBD. The households occupy the residential area. We assume that the CBD is located at the left-side end of the linear territory. As we will get the same conclusions if we locate the $\mathrm{CBD}$ at the center of the linear system, the specified urban configuration will not affect our discussion.

The system consists of industrial and housing sectors. The industrial production is the same as that in the one-sector neoclassical growth model. We assume that the industrial product can be either invested or consumed. The housing production is similar to that in the Muth model. Housing is supplied with combination of capital and land. We assume that the total labor force is fully employed by the industrial sector. We select industrial good to serve as numeraire. As we assume that the transportation cost of workers to the CBD is dependent on the travel distance, land rent for housing should be spatially different. Let $N$ and $\bar{N}(t)$ respectively stand for fixed population and the total labor input at time $t$. We assume that industrial production is carried out by combination of capital and labor force in the form of $F\left(K_{i}(t), \bar{N}(t)\right)$, where $K_{i}(t)$ is capital stocks employed by the industrial sector. Assume $F$ to be neoclassical [3]. Introduce $k_{i} \equiv K_{i} / \bar{N}$. We have

$$
f\left(k_{i}\right) \equiv \frac{F\left(K_{i}, \bar{N}\right)}{\bar{N}}=F\left(k_{i}, 1\right) .
$$

The function, $f\left(k_{i}\right)$, has the following properties: 1) $f(0)=0 ; 2) f\left(k_{i}\right)$ is increasing, strictly concave on $R^{+}$, and $C^{2}$ on $R^{++} ; f^{\prime}\left(k_{i}\right)>0$ and $f^{\prime \prime}\left(k_{i}\right)<0$; and 3) $\lim _{k_{i} \rightarrow 0} f^{\prime}\left(k_{i}\right)=\infty$ and $\lim _{k_{i} \rightarrow+\infty} f^{\prime}\left(k_{i}\right)=0$.

Markets are competitive; thus labor and capital earn their marginal products, and firms earn zero profits. The rate of interest, $r(t)$, and wage rates, $w(t)$, are determined by markets. Hence, for any individual firm $r(t)$ and $w(t)$ are given at each point of time. The production sector chooses the two variables, $K_{i}(t)$ and $\bar{N}(t)$, to maximize its profit. The marginal conditions are given by

$$
r+\delta_{k}=f^{\prime}\left(k_{i}\right), \quad w=f\left(k_{i}\right)-k_{i} f^{\prime}\left(k_{i}\right),
$$

where $\delta_{k}$ is the depreciation rate of physical capital.

We now describe housing production and behavior of households. We us $\omega$ to denote distance from the CBD to a point in the residential area. The total labor input, $\bar{N}(t)$, is the sum of the labor input over the space. Let $T(\omega, t)$ and $T_{h}(\omega, t)$ respectively stand for work time and leisure time of a household at location $\omega$, and $n(\omega, t)$ and $L_{h}(\omega, t)$ respectively for the residential density and lot size of a household at location $\omega$. According to the definitions of $n(\omega, t), T(\omega, t)$ and $\bar{N}(t)$, we have

$$
\bar{N}(t)=\int_{0}^{L} n(\omega, t) T(\omega, t) \mathrm{d} \omega .
$$

Residential housing assets play a dual in the economy. First, residential housing assets are used as a durable consumption good. They are the source of housing services. Residential housing assets are used as a mechanism for the intertemporal transfer of wealth, which generates both rents and capital gains through housing appreciation. It is well known that Muth introduces a commodity "housing" rather than land in describing dwelling conditions. Housing is produced with land and non-land inputs. Households have a derived demand for land, dependent on both preferences for housing and technical characteristics of housing production function. We follow this approach in explaining decision making of dwelling sites of households. The housing industry supplies housing services by combining land and capital. Let us denote $c_{h}(\omega, t)$ housing service received by the household at location $\omega$. We specify the housing service production function as follows

$c_{h}(\omega, t)=k_{h}^{\alpha_{h}}(\omega, t) L_{h}^{\beta_{h}}(\omega, t), \alpha_{h}+\beta_{h}=1, \alpha_{h}, \beta_{h} \geq 0$,

where $k_{h}(\omega, t)$ is the input level of capital per household 
at location, $\omega$. Here, we assume that housing capital can be instantaneously adjusted. All the characteristics of houses such as the size of a lot and the size of a house can be changed instantaneously without costs. Hence the capital-land ratio is always perfectly adjusted. It should be note that our approach is mainly based on [4]. The Anas housing production includes the labor input. Further issues related to the durability of real estates and its costly conversion and replacements are also discussed in [4]. See also [5-8] for introducing more realistic aspects of housing market to the growth model. A recent literature review is referred to [9].

Let $R(\omega, t)$ and $R_{h}(\omega, t)$ stand for respectively the land rent and housing rent at $\omega$. The marginal conditions are given by

$$
r+\delta_{k}=\frac{\alpha_{h} R_{h} c_{h}}{k_{h}}, \quad R=\frac{\beta_{h} R_{h} c_{h}}{L_{h}}, 0 \leq \omega \leq L .
$$

According to the definitions of $L_{h}$ and $n$, we have

$$
n(\omega, t)=\frac{1}{L_{h}(\omega, t)}, \quad 0 \leq \omega \leq L .
$$

The total capital stocks employed by the housing sector is equal to the sum of the capital stocks for housing over space at any point of time.

The relationship between $k_{h}(\omega, t)$ and the total capital stocks employed by the housing sector, $K_{h}(t)$, is given by

$$
K_{h}(t)=\int_{0}^{L} n(\omega, t) k_{h}(\omega, t) d \omega .
$$

Each worker may get income from land ownership, wealth ownership and wages. In order to define incomes, it is necessary to determine land ownership structure. It can be seen that land properties may be distributed in multiple ways under various institutions. There are three often-applied assumptions in the literature of urban economics. They are the absentee landownership, the public ownership, and the equally shared landownership. The absentee landownership assumption means that land is owned by absentee landlords who spend their land incomes outside the economic system. This may also be interpreted as that the government spends the income from land on public goods such as military and households equally benefit from the public goods. If the public goods enter the utility in the following way, $H(g) U(x)$ where $H(g)$ is a function of the public goods, $g$ being independent of location and $x$ is the vector of the other factors that affect the utility, the model is mathematically identical to the interpretation just described. In the case of the public ownership, for instance as accepted in [10], the city government rents the land from the landowners at certain rent and sublets it to households at the market rent, using the net revenue to subsidize city residents equally. The equally shared landownership means that the land is equally shared by the population and the income from the land is equally shared among the population. To simplify the model, we assume the absentee landownership. This means that the income from land rent is spent outside the economic system.

We assume that agents have perfect foresight with respect to all future events and capital markets operate frictionless. The government levies no taxes. Money is introduced by assuming that a central bank distributes at no cost to the population a per capita amount of fiat money $M(t)>0$. The government may distribute the money in various ways and there are different mechanisms for the government to issue money. As systematically demonstrated in [2], it is possible to build the model according to specified characters of the monetary system. The scheme according to which the money stock evolves over time is deterministic and known to all agents. With $\mu$ being the constant net growth rate of the money stock, $M(t)$ evolves over time according:

$$
\dot{M}(t)=\mu M(t), \quad \mu>0 .
$$

At $t$ the government brings $\mu M(t)$ additional units of money per capita into circulation in order to finance all government expenditures via seigniorage. Let $m(t)$ stand for the real value of money per capita measured in units of the output good, that is, $m(t)=M(t) / P(t)$. The government expenditure in real terms per capita, $\tau(t)$, is given by

$$
\tau(t)=\frac{\dot{M}(t)}{P(t)}=\frac{\mu M(t)}{P(t)}=\mu m(t) .
$$

The representative household receives $\mu m(t)$ units of paper money from the government through a "helicopter drop", also considered to be independent of his money holdings. Consumers make decisions on choice of lot size, consumption level of commodity as well as on how much to save. Let $\bar{m}(\omega, t)$ and $k(\omega, t)$ stand for respectively the per capita real money balances and wealth (excluding land) owned by the typical household in at location $\omega$. Each household at $\omega$ obtains the real income

$$
\begin{aligned}
y(\omega, t) & =r(t) k(\omega, t)+w(t) T(\omega, t) \\
& -\pi(t) \bar{m}(\omega, t)+\mu m(t), \quad 0 \leq \omega \leq L .
\end{aligned}
$$

The disposable income is given by

$$
\hat{y}(\omega, t)=y(\omega, t)+a(\omega, t),
$$

where $a(\omega, t) \equiv k(\omega, t)+\bar{m}(\omega, t)$. At each point of time, a consumer at location $\omega$ distributes the total available income among holding money, $\bar{m}(\omega, t)$, 
consuming housing goods, $c_{h}(\omega, t)$, saving, $s(\omega, t)$, consumption of goods, $c(\omega, t)$. A household also decides the time distribution among work, leisure and travel to work. It is assumed that the travel time from the CBD to the residential location is only related to the distance and neglect any other effects such on technological change, infrastructure improvement, and congestion on the travel time form the CBD to the residential area. Let $T_{0}$ and $\Gamma(\omega)$ respectively stand for the total available time and the time spent on traveling between the residence and $\mathrm{CBD}$. We should require that the travel time increases in $\omega$. We have

$$
T(\omega, t)+T_{h}(\omega, t)+\Gamma(\omega)=T_{0} .
$$

It should be remarked that in the literature of transportation research there are many empirical and theoretical studies on interactions between travel behavior and land use patterns [e.g., 11-15]. The size and shapes of cities are interacting with daily activities. At this stage of the research, we try to make transport systems and land use pattern as simple as possible because of analytical difficulties. Issues related to economic growth, land use patterns and transport choice will be examined in future. The budget constraint is given by

$$
R_{h}(\omega, t) c_{h}(\omega, t)+c(\omega, t)+s(\omega, t)=\hat{y}(\omega, t) .
$$

This equation means that the consumption and saving exhaust the consumers' disposable personal income. In this study, we take account of travel costs only in terms of the time spent on travels. We neglect the monetary cost for simplicity of analysis. In reality, even transport mode is an endogenous variable, which implies that like housing, transportation service should enter the utility function. Transportation cost is actually related to income [e.g., 16-18].

In his well-known paper, Tobin [19] deals with an isolated economy in which "outside money" (the part of money stock which is issued by the government) competes with real capital in the portfolios of agents within the framework of the Solow growth model. Since then, many models of growth model of monetary economies are built. Clower [20] proposed a model to incorporate the role of money as a medium of exchange through the so-called cash-in-advance (CIA) constraint. The basic idea is to explain the role that money plays in carrying out transactions by introducing transaction technology. The approach holds that goods cannot be exchanged for goods. Stockman [21] developed a growth model through CIA constraints. This study follows the CIA approach in introducing money into growth theory. When deciding about the composition of their portfolios, the household knows in advance that a certain fraction of consumption needs to be financed by payment in cash. Assume that cash has to be held in advance of purchasing goods. We neglect money held for other purposes, such as for production or for investment. According to Stockman, investment should also be taken into account. See [2] for how to take money for different purposes within the framework. The liquidity constraint of the household is formed as

$$
\bar{m}(\omega, t)=\chi_{h} R_{h}(\omega, t) c_{h}(\omega, t)+\chi c(\omega, t),
$$

where $\chi$ and $\chi_{h}$ are positive parameters. We require $0<\chi, \chi_{h}<1$. Substituting the liquidity constraint into the budget constraint yields

$$
\begin{aligned}
& \left(1-\chi_{h}+\chi_{h} \pi(t)\right) R_{h}(\omega, t) c_{h}(\omega, t)+w(t) T_{h}(\omega, t) \\
& +(1-\chi+\chi \pi(t)) c(\omega, t)+s(\omega, t)=\bar{y}(\omega, t),
\end{aligned}
$$

where we use (7), (8) and

$\bar{y}(\omega, t) \equiv(1+r(t)) k(\omega, t)+w(t)\left[T_{0}-\Gamma(\omega)\right]+\mu m(t)$.

The variable, $\bar{y}$, is the "potential" available income for the household at location $\omega$ as the term, $w\left(T_{0}-\Gamma(\omega)\right)$, is the potential wage income. Location choice is closely related to the existence and quality of such physical environmental attributes as open space and noise pollution as well as social environmental quality. We assume that utility level, $U(\omega, t)$, of the household at location $\omega$ is dependent on $T_{h}(\omega, t), \quad c_{h}(\omega, t)$, $s(\omega, t)$, and $c(\omega, t)$

$$
\begin{gathered}
U(\omega, t)=\theta(\omega, t) T_{h}^{\sigma_{0}}(\omega, t) c^{\xi_{0}}(\omega, t) c_{h}^{\eta_{0}}(\omega, t) s^{\lambda_{0}}(\omega, t), \\
\sigma_{0}, \xi_{0}, \eta_{0}, \lambda_{0}>0,
\end{gathered}
$$

in which $\sigma_{0}, \xi_{0}, \eta_{0}$, and $\lambda_{0}$ are a typical person's elasticity of utility of leisure time, industrial goods, housing, and saving at $\omega$. We call $\sigma_{0}, \xi_{0}, \eta_{0}$, and $\lambda_{0}$ propensities to use leisure time, to consume goods, to consume housing, and to hold wealth, respectively. We consider that residential densities may have positive or negative agglomeration effects. We specify the amenity, $\theta(\omega, t)$, at $\omega$ as follows

$$
\theta(\omega, t)=\theta_{1} n^{\vartheta}(\omega, t), \theta_{1}>0 .
$$

The function, $\theta(\omega, t)$, implies that the amenity level at location $\omega$ is related to the residential density at the location. It should be noted that the approach to household behavior is fully explained in [22]. The relations between this approach and the other approaches (such as the Ramsey model, the Solow model, and Keynesian consumption function) are also explained by Zhang. The conditions that households get the same level of utility at any location at each point of time is represented by

$$
U\left(\omega_{1}, t\right)=U\left(\omega_{2}, t\right), \quad 0 \leq \omega_{1}, \omega_{2} \leq L .
$$

Maximizing $U(\omega, t)$ subject to the budget constraint (9) yields 


$$
T_{h}=\frac{\sigma \bar{y}}{w}, c=\xi_{\pi} \bar{y}, \quad c_{h}=\frac{\eta_{\pi} \bar{y}}{R_{h}}, s=\lambda \bar{y},
$$

where

$$
\begin{gathered}
\xi_{\pi} \equiv \frac{\xi}{1-\chi+\chi \pi}, \quad \eta_{h} \equiv \frac{\eta}{1-\chi_{h}+\chi_{h} \pi}, \quad \sigma \equiv \rho \sigma_{0}, \\
\xi \equiv \rho \xi_{0}, \quad \eta \equiv \rho \eta_{0}, \lambda \equiv \rho \lambda_{0}, \quad \rho \equiv \frac{1}{\sigma_{0}+\xi_{0}+\eta_{0}+\lambda_{0}}
\end{gathered}
$$

According to the definition of $s(\omega, t)$, the wealth accumulation for the household at location $\omega$ is given by

$$
\dot{a}(\omega, t)=s(\omega, t)-a(\omega, t), \quad 0 \leq \omega \leq L .
$$

As the state is isolated, the total population is distributed over the whole urban area. The population constraint is given by

$$
\int_{0}^{L} n(\omega, t) \mathrm{d} \omega=N .
$$

The total consumption, $C(t)$, is given by

$$
\int_{0}^{L} c(\omega, t) n(\omega, t) \mathrm{d} \omega=C(t) .
$$

The national real balance is equal to the sum of the real money balances of all the households. That is

$$
\int_{0}^{L} \bar{m}(\omega, t) n(\omega, t) \mathrm{d} \omega=N m(t) .
$$

The assumption that capital is fully employed is given by

$$
K_{i}(t)+K_{h}(t)=K(t) .
$$

where $K(t)$ I the total capital stock of the economy. The total capital stocks employed by the production sectors is equal to the total wealth owned by all the households. That is

$$
\int_{0}^{L} k(\omega, t) n(\omega, t) \mathrm{d} \omega=K(t) .
$$

We have thus built the dynamic growth model with endogenous spatial distribution of real money balance, wealth, consumption and population, capital accumulation and residential location. We now examine dynamic properties of the system.

\section{The Spatial Equilibrium}

This section examines equilibrium of the spatial dynamics. We are only concerned with equilibrium of the dynamic system because it is difficult to find out explicit expressions of the motion of the system. The following lemma shows the determination of an equilibrium point. The lemma also provides the procedure to determine the equilibrium values of all the variables. The procedure is important for simulation.

\section{Lemma 1}

The equilibrium value of the capital density, $k_{i}$, of the industrial sector is determined by

$$
H\left(k_{i}\right)-\left(\frac{\lambda}{\chi_{h} \eta_{\pi}+\chi \xi_{\pi}}-1\right) N=0,
$$

where

$$
\begin{gathered}
H\left(k_{i}\right) \equiv\left[\left(\frac{1-\sigma-\lambda \mu}{\lambda w}\right) H_{0}\left(k_{i}\right)+\mu\right] \\
{\left[\left(\frac{1-\sigma}{\alpha_{h} \eta_{\pi}}\right) f^{\prime}-\left(\frac{1-\sigma-\delta \lambda-\lambda f^{\prime}}{\lambda w}\right) H_{0}\left(k_{i}\right)\right]^{-1} N,} \\
H_{0}\left(k_{i}\right) \equiv\left(f^{\prime}+\delta\right) k_{i}+w+\left(\frac{1-\sigma}{\alpha_{h} \eta_{\pi}}\right) f^{\prime} k_{i}, \\
\delta \equiv 1-\delta_{k}, \lambda_{\pi} \equiv \frac{\xi_{\pi}+\lambda}{\alpha_{h} \eta_{\pi}} .
\end{gathered}
$$

For a positive solution $k_{i}$, the other variables are determined as follows. The rate of interest and wage, $r$ and $w$, are determined by (1). The average real money per capita, $m$, is determined by the following equation

$$
\left[T_{0}-\left[\int_{0}^{L} \frac{\mathrm{d} \omega}{\Gamma_{1}^{\beta_{0}}(\omega, m)}\right]^{-1} \int_{0}^{L} \frac{\Gamma(\omega)}{\Gamma_{1}^{\beta_{0}}(\omega, m)} \mathrm{d} \omega\right] \frac{N}{m}=H_{m}\left(k_{i}\right),
$$

where

$$
\begin{gathered}
H_{m}\left(k_{i}\right) \equiv \frac{H\left(k_{i}\right)}{k_{i}}-\left(\frac{\alpha_{h} \eta}{k_{i} f^{\prime}}-\frac{\sigma}{w}\right)\left(\frac{H\left(k_{i}\right)+N}{\lambda}\right), \\
\Gamma_{1}(\omega, m) \equiv \Gamma_{0}(\omega)+\mu_{m} m, \Gamma_{0}(\omega) \equiv \frac{\mu_{m}}{\mu} w\left[T_{0}-\Gamma(\omega)\right], \\
\beta_{0} \equiv \frac{1 / \eta_{0} \rho-\beta_{h}}{\vartheta / \eta_{0}-\beta_{h}}, \quad \mu_{m} \equiv \frac{\mu}{1 / \chi_{0}-(1+r)\left(\lambda / \chi_{0}-1\right)} .
\end{gathered}
$$

The real money per capita at location $\omega$ is given by $\bar{m}(\omega)=\Gamma_{1}(\omega, m)$. The equilibrium values of all the other variables are determined by the following procedure: $\pi=\mu \rightarrow n(\omega)$ by (A19) and (A20) $\rightarrow \bar{y}(\omega)$ by (A17) $\rightarrow \bar{m}(\omega)=\Gamma_{0}(\omega)-\mu_{m} m \rightarrow R_{h}(\omega)$ by $(\mathrm{A} 15) \rightarrow$ $T_{h}(\omega), \quad c(\omega), \quad c_{h}(\omega)$ and $s(\omega)$ by $(11) \rightarrow T(\omega)=$ $T_{0}-T_{h}(\omega)-\Gamma(\omega) \rightarrow k_{h}(\omega)$ by (A14) $\rightarrow k(\omega)$ by $(\mathrm{A} 10) \rightarrow K$ by (A8) $\rightarrow \bar{Y}$ by (A2) $\rightarrow \bar{N}$ by (A3) $\rightarrow K_{i}=k_{i} \bar{N} \rightarrow K_{h}=K-K_{i} \rightarrow F=F\left(K_{i}, \bar{N}\right) \rightarrow$ $L_{h}(\omega)=1 / n(\omega) \rightarrow c_{h}(\omega)=k_{h}^{\alpha_{h}}(\omega) L_{h}^{\beta_{h}}(\omega) \rightarrow R(\omega)$ by (4).

The proof of the lemma is available from the author. As it is difficult to interpret conditions for existence of meaningful equilibrium, we will simulate the model to 
illustrate the behavior of the model. Before simulation, we examine some properties of the model. By equations (A15) and (A17), we have

$$
\frac{R_{h}\left(\omega_{1}\right)}{R_{h}\left(\omega_{2}\right)}=\left(\frac{\Gamma_{0}\left(\omega_{2}\right)}{\Gamma_{0}\left(\omega_{1}\right)}\right)^{\left(\beta_{0}-1\right) \beta_{h}},
$$

where we use (19). We have $R_{h}\left(\omega_{1}\right)>R_{h}\left(\omega_{2}\right)$ if $\omega_{1}>\omega_{2}$. The housing rent is higher nearer the CBD. From (A17), we see that $\bar{y}(\omega)$ falls in $\omega$. From equations (11), we see that the leisure time, $T_{h}(\omega)$, and consumption level of the industrial goods, $c(\omega)$, fall in the distance. From $R_{h}(\omega) c_{h}(\omega)=\eta \bar{y}(\omega)$ and (20)

$$
\frac{c_{h}\left(\omega_{1}\right)}{c_{h}\left(\omega_{2}\right)}=\left(\frac{\Gamma_{0}\left(\omega_{1}\right)}{\Gamma_{0}\left(\omega_{2}\right)}\right)^{\beta_{h} \beta_{0}+\alpha_{h}} .
$$

Under the requirement of $\beta_{0}<0$, the housing consumption per household rises (decreases) in distance if $\beta_{h} \beta_{0}+\alpha_{h}>0\left(\beta_{h} \beta_{0}+\alpha_{h}<0\right)$. As

$$
T(\omega)=T_{0}-\Gamma(\omega)-\frac{\sigma \bar{y}(\omega)}{w},
$$

the work time may either fall or rise in distance. It is observed that as we get closer to the city center, not only the population density but also the capital intensity per square miles increase. Buildings tend to be higher near the center. We now explain this phenomenon. The capital-land ratio, $k_{h}(\omega, t) / L_{h}(\omega, t)$, is given by

$$
\begin{gathered}
\frac{k_{h}(\omega, t)}{L_{h}(\omega, t)}=k_{h}(\omega, t) n(\omega, t)= \\
\frac{N \alpha_{h} \eta \bar{y}(\omega)}{\left(r+\delta_{k}\right) \Gamma_{0}^{\beta_{0}}(\omega, m)} \int_{0}^{L} \Gamma_{0}^{\beta_{0}}(\omega, m) \mathrm{d} \omega,
\end{gathered}
$$

where we use equations (A14) and (A20). We have the following corollary.

\section{Corollary 1} CBD.

The capital-land ratio decreases in distance from the

This result is also explained in the Muth model [23].

\section{The Spatial Equilibrium by Simulation}

We have studied the equilibrium problem with the general form of the production function. As it is difficult to explicitly interpret the analytical results, for illustration we simulate the model. This section examines the spatial equilibrium by specifying the production function in the Cobb-Douglas form

$$
F=A K_{i}^{\alpha} \bar{N}^{\beta}, \alpha+\beta=1, \alpha, \beta>0,
$$

where $A$ is the productivity of the industrial sector. We have $f=A k_{i}^{\alpha}$ and

$$
r=\alpha A k_{i}^{-\beta}-\delta_{k}, w=\beta A k_{i}^{\alpha} .
$$

We specify the travel time function as follows

$$
\Gamma(\omega)=v \omega, v,>0,0 \leq \omega \leq L .
$$

Travel time is linearly related to the distance. We specify values of the parameters as follows

$$
\begin{gathered}
A=0.9, \quad N=10, \quad L=1.5, \quad \alpha=0.3, \quad \alpha_{h}=0.45, \\
\eta_{0}=0.09, \quad \xi_{0}=0.12, \quad \sigma_{0}=0.07, \quad \chi=0.2, \quad \chi_{h}=0.1, \\
\mu=0.04, \quad \lambda_{0}=0.75, \quad \vartheta=-0.2, \quad \mu=0.02, \quad T_{0}=1, \\
\theta_{1}=2, \quad \vartheta=-0.2, \quad v=0.05, \quad \delta_{k}=0.06 . \quad
\end{gathered}
$$

The population is fixed at 10 units and the urban size is fixed at 1.5 units. The total productivity is specified with 0.9 and $\alpha$ with 0.3 . The propensities to consume goods and consume housing are respectively equal to 0.12 and 0.9 , which implies that the ratio between the expenditures on goods and housing is $4 / 3$. The propensity to use leisure is equal to 0.07 . The amenity parameter, $-\vartheta$, is negative. This implies that the households prefer to living in an area with low residential distribution. It is assumed that consumption of goods and housing are required be financed 20 percent and 10 percent, respectively, by payment in cash. The total available time is fixed at unit and $v=0.05$ means that the total travel time from the CBD to the other end of the system will use 7.5 per cent of the total available time. The depreciation rate is specified at 0.06 .

We plot Equations (18) and (19) in Figure 1. For the given parameters, the equations have unique solutions.

Following Lemma 1 with (22), we calculate the equilibrium values of the location-independent variables as follows

$$
\begin{gathered}
k_{i}=2.095, \quad f=1.1234, \quad w=0.785, \quad r=0.101, \\
m=0.124, \quad \bar{N}=6.867, \quad K=22.247, \quad K_{i}=14.364, \\
K_{h}=7.884, \quad F=7.704, \quad C=4.641, \quad S=23.489 .
\end{gathered}
$$

The share of the capital employed by the housing sector is lower than the capital stocks employed by the industrial sector. The total labor input, $\bar{N}$, is about 6.87. As the total potential labor input is equal to 10 , about 31 per cent of the potential labor is used for lei-
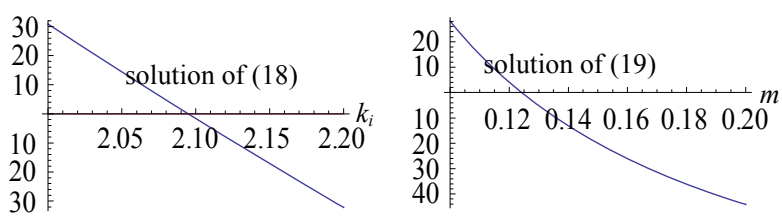

Figure 1. Capital intensity and average real money holding. 
sure and travel. Here, the "potential labor input" is the labor input if all workers spend all their available time on working without traveling and enjoying leisure. In this study, we neglect other possible relations between work time and work efficiency. The rate of interest is about 7.9 percent. We now plot the equilibrium values of the location-dependent variables as in Figure 2. The residential density, consumption of goods, physical wealt per capita and real money per capita decline in distance. Both the housing rent and land rent fall and amenity rises in distance. The consumption of housing and work time rises in distance. As the resident lives further away from the $\mathrm{CBD}$, the leisure time falls.

\section{Changes in the Inflation Policy, CIA Parameter and Transportation}

The previous sector shows the equilibrium structure of the economic geography. We now examine effects of change in the inflation policy parameter, $\mu$, on the equilibrium. Let a variable $\bar{\Delta} x$ stand for the change rate of the variable $x$ in percentage due to changes in value of a parameter value. Suppose that the government increases its inflation policy, $\mu$, from 0.04 to 0.05 . We represent the effects in (24) and Figure 3. As it is well known that in the traditional CIA models the role of money as facilitator of transactions is reflected in the rule that no transactions can take place unless the money needed for the transaction is held for some time in advance. We see that money is not neutral in the long term, as demonstrated in (24) and Figure 3 . We note that although a rise in the growth rate of money reduces the total capital stock and capital stocks employed by the two sectors, the output of goods is increased. As people's income fall, they tend to work longer hours so that the total labor input is increased. From Equations (11), we see that a rise in the growth rate of money implies that the real price of consumption goods and real housing rent are increased. As the prices rise, the demand for goods and housing tend to fall, which would reduce the output levels. As wage falls and rate of interest rises, people tend to have lower income, which make people to work longer hours. People in all the location have more leisure time. The residential density falls nearer the $\mathrm{CBD}$ but increases far away from the CBD. As a consequence of the residential redistribution over space, some people reduce their work hours but some increase their work hours. As a net result, the total labor input is increased. As the inflation rate becomes higher, people at any location reduces their
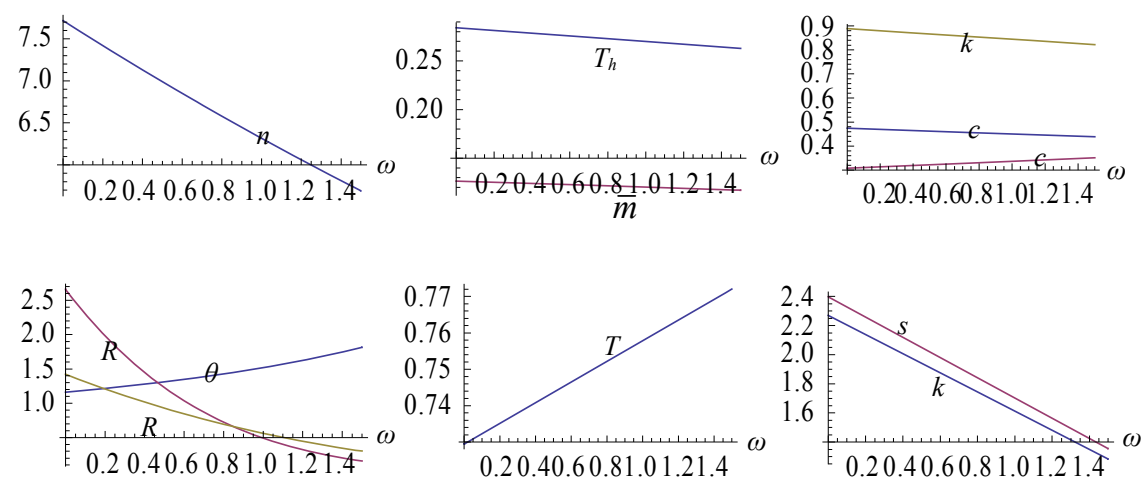

Figure 2. The location-dependent variables.
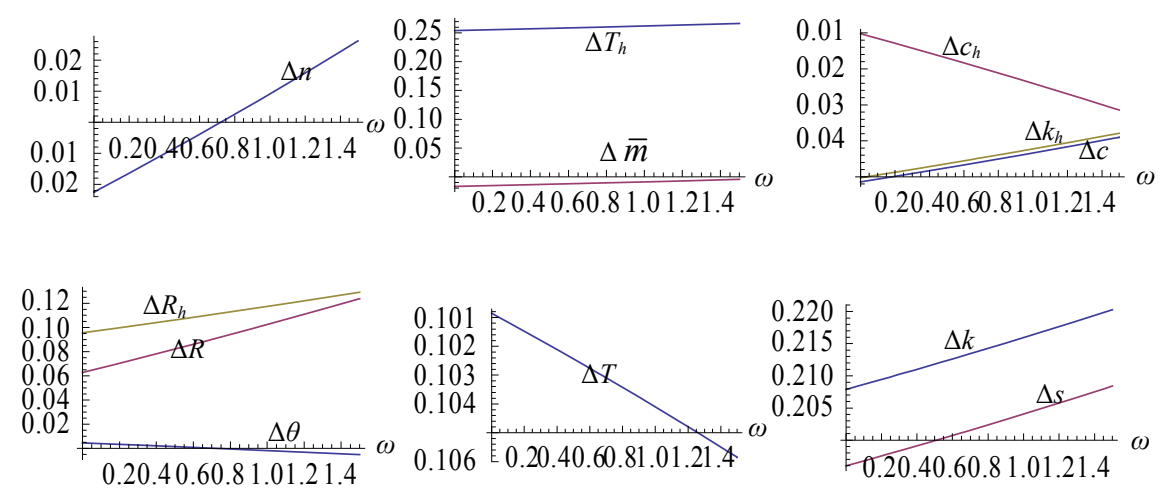

Figure 3. The inflation rate and spatial equilibrium. 
holdings of real money. The consumption levels of goods and housing are reduced at all locations. The amenity is slightly affected. The land and housing rents are increased over space. We also show that the net wealth, $k+\bar{m}$, is increased at any location.

$$
\begin{aligned}
\Delta k_{i} & =-0.193, \Delta f=\Delta w=-0.058, \Delta r=0.216, \\
\Delta K & =-0.209, \Delta K_{i}=-0.128, \Delta K_{h}=-0.356, \\
\Delta F & =0.008, \Delta C=-0.467, \Delta S=-0.220, \\
\Delta m & =-0.433, \Delta \bar{N}=0.066 .
\end{aligned}
$$

We reduce the rate of the cash-in-advance for goods, $\chi$, from 0.2 to 0.1 . The changes are respectively represented in (25) and Figure 4. The capital intensity, output per work time and wage rate are reduced. The total work time and output are increased. The average real money holding and total consumption level are reduced. The total capital stocks and the capital stocks employed by the two sectors are reduced. The model predicts that the total capital stock is reduced, but the total output is increased. From Equations (11), we see that a fall in $\chi$ means that the price of goods falls. We also see that the relative propensity to save, $\lambda$, falls as $\chi$ falls. Since the growth mechanism is neoclassical, we see that the fall in the propensity to save tends to reduce capital stocks in the long term. Our model is different from the traditional neoclassical model in that the work time is an endogenous variable. We see that the net result of rises in the total work time and the fall in the capital stocks increases the total output. The holding of real money per capita at any location falls. The leisure time at any location is increased. The residential density rises near the CBD but alls far away from the CBD. The land rent and housing rent are increased. It should be noted that We also show that a fall in the CIA parameter for housing consumption has the same effects on the equilibrium as these of the change in the CIA parameter for consumption of goods. We will not present the simulation results here.

$$
\begin{gathered}
\Delta k_{i}=-17.819, \Delta f=\Delta w=-5.718, \Delta r=23.483, \\
\Delta m=-53.645, \Delta \bar{N}=6.531, \Delta K=-19,032, \\
\Delta K_{i}=-12.452, \Delta K_{h}=-31.098, \Delta F=0.440, \\
\Delta C=-29.266, \Delta S=-20.862 .
\end{gathered}
$$

Improvement in transportation conditions and economic growth affect urban pattern formation and land use patters. As our growth model explicitly takes account of travel time, we can examine issues related to effects of changes in transportation conditions upon the economic structure and spatial formation. First, we examine the spatial equilibrium structure when the travel speed, $1 / v$, is changed. Let the parameter, $v$, falls from 0.05 to 0.04 . The effects on the space-independent variables are given in (26). A decrease in $v$ implies an increase in the travel speed. The variables, $k_{i}, f, w$, and $r$ are not affected by changes in the travel speed. From Lemma 1, we see that the capital intensity of the industrial sector is not affected by the travel speed. As the output level of per unit labor input, the rate of interest and the wage rate per unit of labor input are uniquely determined by the capital intensity and technology of the industrial sector, we see that the change in the speed has no effects on these variables. Although these variables are not affected, a household's income from wage and the total output will be affected because these variables are affected by the change in the time distribution. The variables, $m, \bar{N}, K, K_{i}, K_{h}, F, C$, and $S$, are increased in the same proportion. We provide the simulation results for the space-dependent variables as in Figure 5. As the travel time at fixed location to the urban center is reduced, the household at that location will increase leisure time and work time. Under the given preference for leisure time, we see that different from the case of technological improvement in the industrial sector, as the travel is sped up, the total work input is increased due to the increase in the total work time. As the total labor input is increased, the output is increased. The increase in
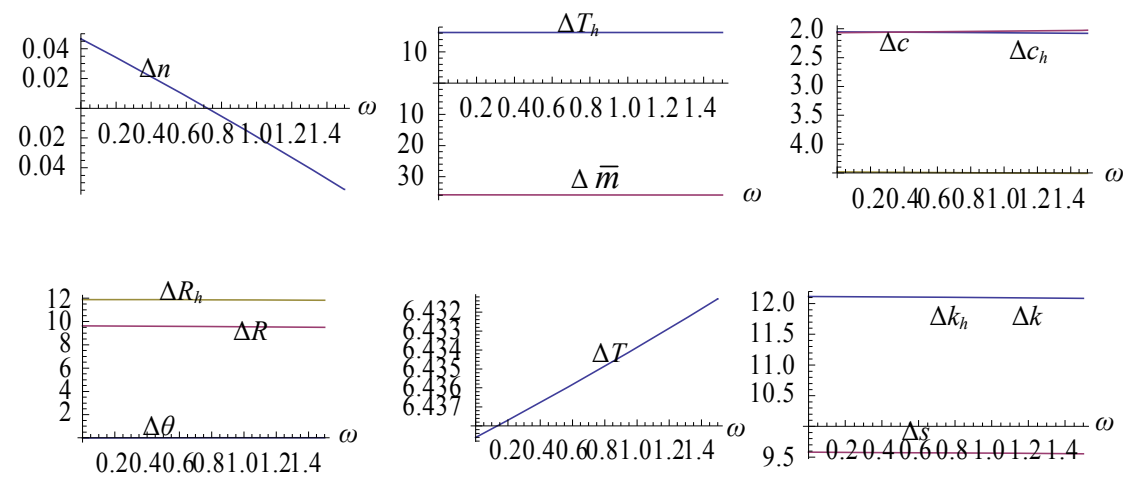

Figure 4. The effects of a fall in the CIA parameter. 

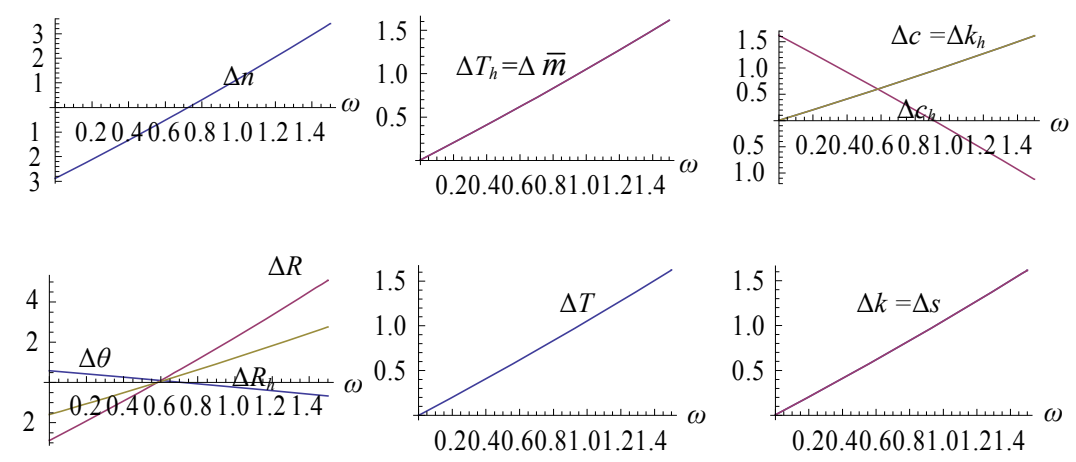

Figure 5. A rise in travel speed and spatial equilibrium.

the output increases the savings and the capital stocks. We see that as a consequence of the improvement in travel speed, the macroeconomic performance of the economy is improved. Here, we remark that a limitation of our model is that we don't take account of the costs for improving the transportation system. If we take account of the costs (which are paid by tax income either on households or the production sector), the conclusions for the macroeconomic performance may not be always positive. As transportation conditions are improved, the residential density falls near the CBD and rises far away from the $\mathrm{CBD}$. The land rent and rent of housing rise and fall where the residential density falls and rises. The consumption level of goods, capital stock and real money holding per household at any location are increased. The amenity and consumption of housing rise near the $\mathrm{CBD}$ and fall far away from the CBD.

$$
\begin{gathered}
\Delta k_{i}=\Delta f=\Delta w=\Delta r=0, \Delta m=\Delta \bar{N}=\Delta K=0.706, \\
\Delta K_{i}=\Delta K_{h}=\Delta F=\Delta C=\Delta S=0.706 .
\end{gathered}
$$

\section{Conclusions}

This study proposed a spatial monetary growth model with transportation conditions with the CIA approach. First, we defined the model and found the conditions for existence of equilibrium. We simulated the model. The dynamic model with economic geography has a unique long-run equilibrium point with the specified values of the parameters. We also analyzed effects of the changes in the inflation policy and transportation conditions. As we are mainly concerned with interactions of multiple economic forces, each aspect of the whole system might appear over-simplified. Many limitations of this model become apparent in the light of the sophistication of the literature of growth theory [3,24], monetary economics [2], urban economics [23,25], and transportation research. It is important to examine implications of various transportation network structures for economic growth and development. As capital accumulation is endogenous in our model, our study makes it possible to introduce dynamics among infrastructure development, transportation systems, and economic growth, even though resulted models may become analytically less tractable.

\section{Acknowledgements}

I am grateful for the constructive comments of the anonymous referee and a grant-in-aid from the Zengin Foundation for Studies on Economics and Finance.

\section{References}

[1] W. B. Zhang, "Growth and Residential Distribution with Economic Structure and Amenity: A Synthesis of Solow-Uzawa's Growth, Alonso's Urban, and Muth's Housing Models," Papers in Regional Science, Vol. 87, No. 2, 2008, pp. 277-303. doi:10.1111/j.1435-5957.2008.00173.x

[2] W. B. Zhang, "Monetary Growth Theory: Money, Interest, Prices, Capital, Knowledge, and Economic Structure over Time and Space," Routledge, London, 2009.

[3] E. Burmeister and A. R. Dobell, "Mathematical Theories of Economic Growth," Collier Macmillan Publishers, London, 1970.

[4] A. Anas, "Dynamics of Urban Residential Growth," Journal of Urban Economics, Vol. 5, No. 1, 1978, pp. 66-87. doi:10.1016/0094-1190(78)90037-2

[5] M. M. Fischer, K. J. Button and P. Nijkamp, Eds., "Regional Housing and Labour Markets," Edward Elgar, Cheltenham, 1996.

[6] R. J. Arnott, "A Simple Urban Growth Model with Durable Housing," Regional Science and Urban Economics, Vol. 10, No. 1, 1980, pp. 53-76. doi:10.1016/0166-0462(80)90048-4

[7] R. Arnott, R. Braid, R. Davidson and D. Pines, "A General Equilibrium Spatial Model of Housing Quality and Quantity," Regional Science and Urban Economics, Vol. 29, No. 3, 1999, pp. 283-316. doi:10.1016/S0166-0462(98)00035-0

[8] E.L. Glaeser and J. Gyourko, "Urban Decline and Durable Housing," Journal of Political Economy, Vol. 113, No. 2, 2005, pp. 345-375. doi:10.1086/427465 
[9] C. C. Lin, C. C. Mai and P. Wang, "Urban Land Policy and Hosing in an Endogenously Growing Monocentric City," Regional Science and Urban Economics, Vol. 34, No. 3, 2004, pp. 241-261. doi:10.1016/S0166-0462(03)00026-7

[10] Y. Kanemoto, "Theories of Urban Externalities," NorthHolland, Amsterdam, 1980.

[11] D. Banister, "Planning More to Travel Less. Land Use and Transport," Town Planning Review, Vol. 70, No. 3, 1999, pp. 313-338.

[12] M. G. Boarnet and R. Crane, "Travel by Design: The Influence of Urban Form on Travel," Oxford University Press, Oxford, 2001.

[13] S. Srinivasan and J. Ferreira, "Travel Behavior at the Household Level: Understanding Linkages with Residential Choice," Transportation Research D, Vol. 7, No. 3, 2002, pp. 225-242. doi:10.1016/S1361-9209(01)00021-9

[14] K. Maat, K., B. van Wee and D. Stead, "Land Use and Travel Behaviour: Expected Effects from the Perspective of Utility Theory and Activity-based Theories," Environment and Planning B, Vol. 32, No. 1, 2005, pp. 33-46. doi:10.1068/b31106

[15] N. Buchanan, R. Barnett, S. Knigham and D. Johnston, "The Effect of Urban Growth on Commuting Patterns in Christchurch, New Zealand," Journal of Transport Geography, Vol. 14, No. 5, 2006, pp. 342-354. doi:10.1016/j.jtrangeo.2005.10.008

[16] K. Train and D. McFadden, "The Goods/Leisure Tradeoff and Disaggregate Work Trip Mode Choice Models," Transportation Research, Vol. 12, No. 5, 1978, pp.
349-353. doi:10.1016/0041-1647(78)90011-4

[17] P. Rietveld, K., Button, K. and P. Nijkamp, Eds., "Urban Transport," Edward Elgar, Cheltenham, 2003.

[18] A. De Palma, M. Kilani and R. Lindsey, "Congestion Pricing on a Road Network: A Study Using the Dynamic Equilibrium Simulator METROPOLIS," Transportation Research A, Vol. 39, No. 7-9, 2005, pp. 588-611. doi:10.1016/j.tra.2005.02.018

[19] J. Tobin, "The Interest Elasticity of the Transactions Demand for Money," Review of Economics and Statistics, Vol. 38, No. 3, 1956, pp. 241-47. doi:10.2307/1925776

[20] R. W. Clower, "A Reconsideration of the Microfoundations of Monetary Theory," Western Economic Journal, Vol. 6, 1967, pp. 1-9.

[21] A. Stockman, "Anticipated Inflation, and the Capital Stocks in a Cash-in-Advance Economy," Journal of Monetary Economics, Vol. 8, No. 3, 1981, pp. 387-93. doi:10.1016/0304-3932(81)90018-0

[22] W. B. Zhang, "Economic Growth Theory," Ashgate, Hampshire, 2005.

[23] M. Fujita, "Urban Economic Theory_Land Use and City Size," Cambridge University Press, Cambridge, 1999.

[24] A. Takayama, "Mathematical Economics," Cambridge University Press, Cambridge, 1996.

[25] M. Fujita and J.F. Thisse, "Economics of Agglomeration: Cities, Industrial Location, and Regional Growth," Cambridge University Press, Cambridge, 2002. 